\title{
Candidates Cell Sources to Regenerate Alveolar Bone from Oral Tissue
}

\author{
Masahiro Nishimura, Kazuma Takase, Fumio Suehiro, and Hiroshi Murata \\ Department of Prosthetic Dentistry, Graduate School of Biomedical Sciences, Nagasaki University, Sakamoto 1-7-1, \\ Nagasaki 852-8588, Japan \\ Correspondence should be addressed to Masahiro Nishimura, mnishi@nagasaki-u.ac.jp
}

Received 14 October 2011; Accepted 29 November 2011

Academic Editor: Chiaki Kitamura

Copyright ( 2012 Masahiro Nishimura et al. This is an open access article distributed under the Creative Commons Attribution License, which permits unrestricted use, distribution, and reproduction in any medium, provided the original work is properly cited.

\begin{abstract}
Most of the cases of dental implant surgery, especially the bone defect extensively, are essential for alveolar ridge augmentation. As known as cell therapy exerts valuable effects on bone regeneration, numerous reports using various cells from body to regenerate bone have been published, including clinical reports. Mesenchymal cells that have osteogenic activity and have potential to be harvested from intra oral site might be a candidate cells to regenerate alveolar bone, even dentists have not been harvested the cells outside of mouth. This paper presents a summary of somatic cells in edentulous tissues which could subserve alveolar bone regeneration. The candidate tissues that might have differentiation potential as mesenchymal cells for bone regeneration are alveolar bone chip, bone marrow from alveolar bone, periosteal tissue, and gingival tissue. Understanding their phenotype consecutively will provide a rational approach for alveolar ridge augmentation.
\end{abstract}

\section{Introduction}

For increasing the success rate of implant surgery, various scaffolds and methods have been developed to augment atrophic alveolar ridge. Generally, autologous bone augmentation has been penetrating as a golden standard bone augmentation; however, most of the patients might not be feasible for extracting their own bone, just because it is a healthy part. To avoid aforementioned high-invasive treatments, cell therapy has recently been researched in this age of rapid advance.

Combination of mesenchymal cells and ceramic scaffold for bone regeneration has been documented [1]. Cultured mesenchymal cells introduced into ceramic scaffolds exhibits robust osteogenic potential, with bone forming into pore regions of scaffolds. After this report, numerous reports using various cells to regenerate bone and sophisticate reviews for bone regeneration of craniofacial site have been published [2-7]. Usage of tooth, including periodontal ligament or pulp, has also been reported that multipotential stromal cells which are composed above mentioned were exploited in bone or periodontal regeneration $[8,9]$.
Although bone augmentation is mostly fundamental to elderly, they unfortunately follow to edentulous patients in aging society. Thus, this paper focuses on adult mesenchymal cells that could be able to expand from edentulous jaw. Figure 1 shows the tissues we describe in this paper by sectional scheme of edentulous alveolar ridge.

\section{Alveolar Bone Chips}

Osteoblasts-like cells migrated from alveolar bone chips have generally high osteogenic activity. Essentially, mammalian bones are in the form of two different ways: long bones via endochondral ossification and flat bones via intramembranous ossification. Orofacial bone is mainly formed via intramembranous ossification, and a part of mandibular is formed via endochondral ossification. These bony types show considerable differences in protein composition [10]. Harvesting bony chips from various sites implicate that origins of the osteoblastic cells (from maxilla or mandibular, from cortical or trabecular bone) are distinct from each reports; furthermore osteogenic activity, expression 


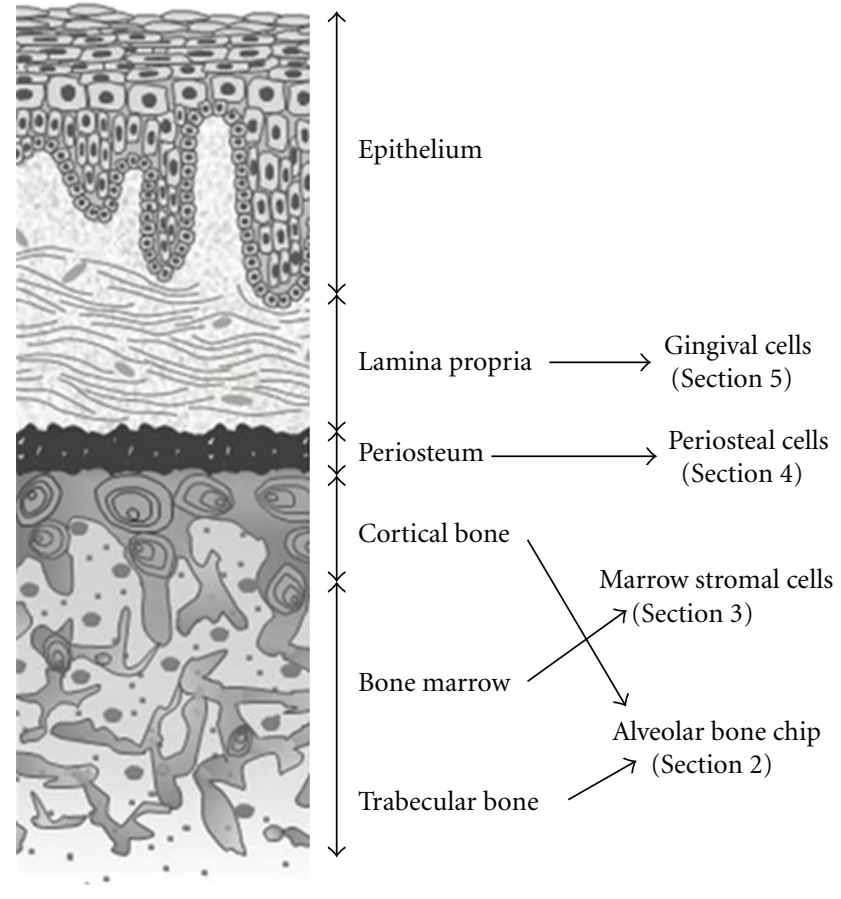

Figure 1: Sectional scheme of edentulous alveolar ridge. Figure shows the origin of candidate tissues and the cells we could harvest from alveolar bone chip, bone marrow, periosteum, and gingiva.

of surface antigens, or ability for ectopic bone formations might be different among each report, beside cell isolation protocols are different among each report. Majority of culture protocol of osteogenic cells from alveolar bone are wash bone specimens in PBS, scrape to remove attached soft tissue and periosteum, brake into small pieces, and wash with collagenase ( 1 to $2 \mathrm{mg} / \mathrm{mL}$ ) dissolved in culture medium $[11,12]$. In some reports, osteogenic cells were collected without collagenase [13-15]. However, despite harvesting bony chips from healthy site is essential when we use these in clinic, it is not feasible for all patients just because of the invasive operation. In addition, it is still not clear how amount of bony chips is enough to regenerate each part of alveolar ridge and which part of bone cells are suitable to keep augmented bone volume on long prognosis.

\section{Bone Marrow from Alveolar Bone}

The reason why iliac crest bone marrow is the most documented bone marrow transplantation is because they have been corrected for bone marrow transplantation in clinic as usual. Bone marrow stromal cells (BMSCs) have been reported their ability of multipotent differentiation to bone, cartilage, tendon, muscle, adipose tissue, and neuronal tissue [16-18]. Bone regenerative clinical studies using BMSCs, collected from iliac crest to reconstruct jaw defects, have been reported $[19,20]$. Kawaguchi et al. reported that iliac crest BMSCs enhance periodontal tissue regeneration as well [21, 22]. Alveolar BMSCs, however, is essentially different from axial BMSCs from their differential potential or their gene expression pattern [23, 24]. Embryologically, alveolar tissues including alveolar bone marrow are originated from neural crest cells, but other bone marrows are from mesoderm $[25,26]$. Cherubism [27], Treacher Collins syndrome [28], craniofacial fibrous dysplasia [29], and hyperparathyroid jaw tumor syndrome [30] affect only jaw bones, indicating that orofacial bone development differs from that of axial and appendicular bone formation. Whitaker's group have reported that membranous bone underwent less resorption than endochondral bone in monkey model [31], and they found the rapid vascularization on membranous onlay bone grafts in rabbit model [32]. In human alveolar cleft defects, chin bone was better incorporated, significantly less resorbed than iliac crest bone $[33,34]$. In histomorphometry, autologous grafts obtained from calvarial sources for sinus lift procedure present a significantly higher degree of bone volume in contrast to bone harvested from the iliac crest [35]. In in vitro and in vivo study, Akintoye et al. have investigated skeletal site-specific phenotypic and functional differences between orofacial (maxilla and mandible) and axial (iliac crest) human BMSCs. Compared with iliac crest cells, orofacial BMSCs proliferated more rapidly with delayed senescence, expressed higher levels of alkaline phosphatase, and demonstrated more calcium accumulation in vitro. Orofacial BMSCs formed more bone in vivo, while iliac crest BMSCs formed more compacted bone that included hematopoietic tissue and were more responsive in vitro and in vivo to osteogenic and adipogenic inductions [36]. Comparing with the osteogenic properties of BMSCs attached on titanium for evaluating the avidity bone to implant exhibited that there was no difference in the affinity of maxilla and iliac crest BMSCs to titanium. Titanium-attached maxilla BMSCs, however, were apparently more osteogenically responsive than iliac crest cells based on calcium accumulation and gene expression of alkaline phosphatase and osteopontin [37]. Akintoye et al. have also studied the skeletal site-specific osteogenic response of BMSC to BMP-2 stimulation [38]. They reported orofacial BMSC displayed high expression of osteogenic markers in response to BMP-2 in contrast to the low response of adult iliac crest BMSC. They also reported that mandible BMSCs were more susceptible to bisphosphonates than iliac crest BMSC [39]; orofacial BMSC survived higher radiation doses and recovered quicker than iliac crest BMSC [40]. Osteoclastogenic potential of jaw and long-bone-derived osteoclasts have different dynamics, and this might primarily due to differences in the cellular composition of the bone site-specific marrow [41]. Aghaloo et al. established a protocol for rat mandible and long-bone marrow stromal cell isolation and culture. Upon implantation into nude mice, mandible BMSCs formed 70\% larger bone nodules containing three-fold more mineralized bone compared with long-bone BMSCs [42]. Alveolar BMSCs are obtained from older individuals, and the donor age has little effect on their gene expression pattern [43]. According to aforementioned studies, usage of alveolar BMSCs might have high advantages for alveolar bone regeneration compared with iliac BMSCs; however, establishing the protocol of harvesting BMSCs in low invasive way is still unclear. 


\section{Periosteal Tissue from Oral Site}

Usage of periosteal cells from periosteum was originally reported by Breitbart et al. on rabbit experiments [44]. Outgrowthed periosteal cells were cultured with dexamethasone contained medium, and cell/polyglycolic acid nonwoven fiver scaffolds complex showed significant bone formation on calvarial defect compared with scaffold only. Adult human periosteal cells from tibia include multipotent clonogenic cells [45], while, in the case of oral tissue, periosteal cells isolated from the mandibular angle of human with $\beta$-tricalcium phosphate granules have shown that combined treatment with bFGF and BMP-2 can make periosteal cells a highly useful source of bone regeneration [46]. In nude mouse subcutaneously model, acid-treated HA block cultured with human periosteal cells complex had significant osteogenic potential at the site of implantation in vivo [47], while in canine model for peri-implant bone regeneration, periosteum-derived cells in conjunction with e-PTFE membranes did not provide additional benefit [48]. Comparing with proliferated periosteal cells, Cicconetti et al. harvested marrow cells from maxillary tuberosity bone. They concluded that both periosteal cells and marrow stromal cells showed comparable phenotypic profiles and both cell populations formed bone upon ectopic in vivo transplantation [49]. Harvesting periosteal cells is relatively invasive treatment; for instance, it is still unclear the collection quantity for required bone regeneration and also periosteal tissue is hard to collect by general practitioners.

\section{Gingival Tissue}

During dental surgery, gingival tissue could be obtained frequently as a discarded biological sample. Wound healing within the gingiva is characterized by markedly reduced inflammation, scarless healing, rapid reepithelialization, contrary to the common scar formation present in skin $[50,51]$. Recently, several reports have indicated the presence of progenitor cells in gingival connective tissue [52, 53]. Tang et al. reported gingival tissue contains tissue-specific mesenchymal stem cell population and is an ideal resource for immunoregulatory therapy, using human normal and hyperplastic gingival tissues [54]. The ratio of these progenitors in gingival fibroblasts, however, might be very low rather than bone marrow, periosteal tissue, or bone chips. Nevertheless, enrichment of progenitor cells that show characteristics with of differentiation as osteoblastic cells entail for usage in bone tissue engineering.

\section{Conclusion}

Bone marrow-derived cells, called mononuclear cells or marrow mesenchymal cells, are essentially different from osteoblastic cells derived from bone chip. In a case of small animal model, it is hard to separate mandibular bone marrow cells to bone lining osteoblastic cells [55]. In bulk, however, this bone/BMSCs possess unique stem cell properties that the size of alveolar bone has restrained the precise analysis of BMSCs phenotype. Furthermore, diversity of culture methods made us to confuse. As we use outgrowth cells from tissues on the other side, the population cultured cells is influenced by their migration ability. Treating tissue with enzyme to disperse cells from tissue, however, cell population is not dependent on migration ability. Thus, developing stable and universal methods to harvest and culture osteogenic cells for bone regeneration is prerequisite.

\section{References}

[1] H. Ohgushi, V. M. Goldberg, and A. I. Caplan, "Heterotopic osteogenesis in porour ceramics induced by marrow cells," Journal of Orthopaedic Research, vol. 7, no. 4, pp. 568-578, 1989.

[2] G. T. J. Huang, S. Gronthos, and S. Shi, "Mesenchymal stem cells derived from dental tissues vs. those from other sources: their biology and role in regenerative medicine," Journal of Dental Research, vol. 88, no. 9, pp. 792-806, 2009.

[3] H. Kagami and H. Agata, "The potential of somatic stem cells for alveolar bone tissue engineering," International Journal of Oral-Medical Sciences, vol. 9, no. 1, pp. 1-10, 2010.

[4] J. J. Mao, W. V. Giannobile, J. A. Helms et al., "Craniofacial tissue engineering by stem cells," Journal of Dental Research, vol. 85, no. 11, pp. 966-979, 2006.

[5] M. Miura, Y. Miura, W. Sonoyama, T. Yamaza, S. Gronthos, and S. Shi, "Bone marrow-derived mesenchymal stem cells for regenerative medicine in craniofacial region," Oral Diseases, vol. 12, no. 6, pp. 514-522, 2006.

[6] M. V. Risbud and I. M. Shapiro, "Stem cells in craniofacial and dental tissue engineering," Orthodontics \& Craniofacial Research, vol. 8, no. 2, pp. 54-59, 2005.

[7] P. A. Zuk, "Tissue engineering craniofacial defects with adult stem cells? Are we ready yet?” Pediatric Research, vol. 63, no. 5, pp. 478-486, 2008.

[8] T. Iwata, M. Yamato, Z. Zhang et al., "Validation of human periodontal ligament-derived cells as a reliable source for cytotherapeutic use," Journal of Clinical Periodontology, vol. 37, no. 12, pp. 1088-1099, 2010.

[9] H. Ikeda, Y. Sumita, M. Ikeda et al., "Engineering bone formation from human dental pulp-and periodontal ligamentderived cells," Annals of Biomedical Engineering, vol. 39, no. 1, pp. 26-34, 2010.

[10] T. van den Bos, D. Speijer, R. A. Bank, D. Brömme, and V. Everts, "Differences in matrix composition between calvaria and long bone in mice suggest differences in biomechanical properties and resorption. Special emphasis on collagen," Bone, vol. 43, no. 3, pp. 459-468, 2008.

[11] K. Mustafa, A. Wennerberg, J. Wroblewski, K. Hultenby, B. S. Lopez, and K. Arvidson, "Determining optimal surface roughness of $\mathrm{TiO}_{2}$ blasted titanium implant material for attachment, proliferation and differentiation of cells derived from human mandibular alveolar bone," Clinical Oral Implants Research, vol. 12, no. 5, pp. 515-525, 2001.

[12] A. L. Rosa, G. E. Crippa, P. T. de Oliveira, M. Taba, L. P. Lefebvre, and M. M. Beloti, "Human alveolar bone cell proliferation, expression of osteoblastic phenotype, and matrix mineralization on porous titanium produced by powder metallurgy," Clinical Oral Implants Research, vol. 20, no. 5, pp. 472-481, 2009.

[13] H. Perinpanayagam, T. Martin, V. Mithal et al., "Alveolar bone osteoblast differentiation and Runx2/Cbfa1 expression," Archives of Oral Biology, vol. 51, no. 5, pp. 406-415, 2006. 
[14] M. Payer, B. Lohberger, E. Stadelmeyer, C. Bartmann, R. Windhager, and N. Jakse, "Behaviour of multipotent maxillary bone-derived cells on $\beta$-tricalcium phosphate and highly porous bovine bone mineral," Clinical Oral Implants Research, vol. 21, no. 7, pp. 699-708, 2010.

[15] S. Y. Jiang, R. Shu, Z. C. Song, and Y. F. Xie, "Effects of enamel matrix proteins on proliferation, differentiation and attachment of human alveolar osteoblasts," Cell Proliferation, vol. 44, no. 4, pp. 372-379, 2011.

[16] A. J. Friedenstein, K. V. Petrakova, A. I. Kurolesova, and G. P. Frolova, "Heterotopic of bone marrow. Analysis of precursor cells for osteogenic and hematopoietic tissues," Transplantation, vol. 6, no. 2, pp. 230-247, 1968.

[17] R. J. Deans and A. B. Moseley, "Mesenchymal stem cells: biology and potential clinical uses," Experimental Hematology, vol. 28 , no. 8, pp. 875-884, 2000.

[18] A. I. Caplan and S. P. Bruder, "Mesenchymal stem cells: building blocks for molecular medicine in the 21st century," Trends in Molecular Medicine, vol. 7, no. 6, pp. 259-264, 2001.

[19] Y. Yamada, M. Ueda, T. Naiki, M. Takahashi, K. I. Hata, and T. Nagasaka, "Autogenous injectable bone for regeneration with mesenchymal stem cells and platelet-rich plasma: tissueengineered bone regeneration," Tissue Engineering, vol. 10, no. 5-6, pp. 955-964, 2004.

[20] G. J. Meijer, J. D. de Bruijn, R. Koole, and C. A. van Blitterswijk, "Cell based bone tissue engineering in jaw defects," Biomaterials, vol. 29, no. 21, pp. 3053-3061, 2008.

[21] H. Kawaguchi, A. Hirachi, N. Hasegawa et al., "Enhancement of periodontal tissue regeneration by transplantation of bone marrow mesenchymal stem cells," Journal of Periodontology, vol. 75, no. 9, pp. 1281-1287, 2004.

[22] N. Hasegawa, H. Kawaguchi, A. Hirachi et al., "Behavior of transplanted bone marrow-derived mesenchymal stem cells in periodontal defects," Journal of Periodontology, vol. 77, no. 6, pp. 1003-1007, 2006.

[23] T. Matsubara, K. Suardita, M. Ishii et al., "Alveolar bone marrow as a cell source for regenerative medicine: differences between alveolar and iliac bone marrow stromal cells," Journal of Bone and Mineral Research, vol. 20, no. 3, pp. 399-409, 2005.

[24] A. Igarashi, K. Segoshi, Y. Sakai et al., "Selection of common markers for bone marrow stromal cells from various bones using real-time RT-PCR: effects of passage number and donor age," Tissue Engineering, vol. 13, no. 10, pp. 2405-2417, 2007.

[25] Y. Chai, X. Jiang, Y. Ito et al., "Fate of the mammalian cranial neural crest during tooth and mandibular morphogenesis," Development, vol. 127, no. 8, pp. 1671-1679, 2000.

[26] I. H. Chung, T. Yamaza, H. Zhao, P. H. Choung, S. Shi, and Y. Chai, "Stem cell property of postmigratory cranial neural crest cells and their utility in alveolar bone regeneration and tooth development," Stem Cells, vol. 27, no. 4, pp. 866-877, 2009.

[27] Y. Ueki, V. Tiziani, C. Santanna et al., "Mutations in the gene encoding c-Abl-binding protein SH3BP2 cause cherubism," Nature Genetics, vol. 28, no. 2, pp. 125-126, 2001.

[28] J. Dixon, P. Trainor, and M. J. Dixon, "Treacher Collins syndrome," Orthodontics \& Craniofacial Research, vol. 10, no. 2, pp. 88-95, 2007.

[29] M. Riminucci, B. Liu, A. Corsi et al., "The histopathology of fibrous dysplasia of bone in patients with activating mutations of the Gs $\alpha$ gene: site-specific patterns and recurrent histological hallmarks," Journal of Pathology, vol. 187, no. 2, pp. 249-258, 1999.
[30] W. F. Simonds, L. A. James-Newton, S. K. Agarwal et al., "Familial isolated hyperparathyroidism: clinical and genetic characteristics of 36 kindreds," Medicine, vol. 81, no. 1, pp. 126, 2002.

[31] J. E. Zins and L. A. Whitaker, "Membranous versus endochondral bone: implications for craniofacial reconstruction," Plastic and Reconstructive Surgery, vol. 72, no. 6, pp. 778-785, 1983.

[32] J. F. Kusiak, J. E. Zins, and L. A. Whitaker, "The early revascularization of membranous bone," Plastic and Reconstructive Surgery, vol. 76, no. 4, pp. 510-516, 1985.

[33] W. A. Borstlap, K. L. W. Heidbuchel, H. P. M. Freihofer, and A. M. Kuijpers-Jagtman, "Early secondary bone grafting of alveolar cleft defects: a comparison between chin and rib grafts," Journal of Cranio-Maxillo-Facial Surgery, vol. 18, no. 5, pp. 201-205, 1990.

[34] R. Koole, H. Bosker, and F. N. van der Dussen, "Late secondary autogenous bone grafting in cleft patients comparing mandibular (ectomesenchymal) and iliac crest (mesenchymal) grafts," Journal of Cranio-Maxillo-Facial Surgery, vol. 17, supplement 1, pp. 28-30, 1989.

[35] R. Crespi, R. Vinci, P. Capparè, E. Gherlone, and G. E. Romanos, "Calvarial versus iliac crest for autologous bone graft material for a sinus lift procedure: a histomorphometric study," International Journal of Oral and Maxillofacial Implants, vol. 22, no. 4, pp. 527-532, 2007.

[36] S. O. Akintoye, T. Lam, S. Shi, J. Brahim, M. T. Collins, and P. G. Robey, "Skeletal site-specific characterization of orofacial and iliac crest human bone marrow stromal cells in same individuals," Bone, vol. 38, no. 6, pp. 758-768, 2006.

[37] S. O. Akintoye, P. Giavis, D. Stefanik, L. Levin, and F. K. Mante, "Comparative osteogenesis of maxilla and iliac crest human bone marrow stromal cells attached to oxidized titanium: a pilot study," Clinical Oral Implants Research, vol. 19, no. 11, pp. 1197-1201, 2008.

[38] A. M. Osyczka, M. Damek-Poprawa, A. Wojtowicz, and S. O. Akintoye, "Age and skeletal sites affect BMP-2 responsiveness of human bone marrow stromal cells," Connective Tissue Research, vol. 50, no. 4, pp. 270-277, 2009.

[39] D. Stefanik, J. Sarin, T. Lam, L. Levin, P. S. Leboy, and S. O. Akintoye, "Disparate osteogenic response of mandible and iliac crest bone marrow stromal cells to pamidronate," Oral Diseases, vol. 14, no. 5, pp. 465-471, 2008.

[40] M. Damek-Poprawa, D. Stefanik, L. M. Levin, and S. O. Akintoye, "Human bone marrow stromal cells display variable anatomic site-dependent response and recovery from irradiation," Archives of Oral Biology, vol. 55, no. 5, pp. 358-364, 2010.

[41] A. P. D. S. Faloni, T. Schoenmaker, A. Azari et al., "Jaw and long bone marrows have a different osteoclastogenic potential," Calcified Tissue International, vol. 88, no. 1, pp. 63-74, 2011.

[42] T. L. Aghaloo, T. Chaichanasakul, O. Bezouglaia et al., "Osteogenic potential of mandibular vs. long-bone marrow stromal cells," Journal of Dental Research, vol. 89, no. 11, pp. 1293-1298, 2010.

[43] J. Han, H. Okada, H. Takai, Y. Nakayama, T. Maeda, and Y. Ogata, "Collection and culture of alveolar bone marrow multipotent mesenchymal stromal cells from older individuals," Journal of Cellular Biochemistry, vol. 107, no. 6, pp. 1198-1204, 2009.

[44] A. S. Breitbart, D. A. Grande, R. Kessler, J. T. Ryaby, R. J. Fitzsimmons, and R. T. Grant, "Tissue engineered bone repair of calvarial defects using cultured periosteal cells," Plastic and Reconstructive Surgery, vol. 101, no. 3, pp. 567-574, 1998. 
[45] C. de Bari, F. Dell'Accio, J. Vanlauwe et al., "Mesenchymal multipotency of adult human periosteal cells demonstrated by single-cell lineage analysis," Arthritis and Rheumatism, vol. 54, no. 4, pp. 1209-1221, 2006.

[46] H. Agata, I. Asahina, Y. Yamazaki et al., "Effective bone engineering with periosteum-derived cells," Journal of Dental Research, vol. 86, no. 1, pp. 79-83, 2007.

[47] T. Kawase, K. Okuda, H. Kogami et al., "Human periosteumderived cells combined with superporous hydroxyapatite blocks used as an osteogenic bone substitute for periodontal regenerative therapy: an animal implantation study using nude mice," Journal of Periodontology, vol. 81, no. 3, pp. 420427, 2010.

[48] F. V. Ribeiro, F. F. Suaid, K. G. S. Ruiz et al., "Peri-implant reconstruction using autologous periosteum-derived cells and guided bone regeneration," Journal of Clinical Periodontology, vol. 37, no. 12, pp. 1128-1136, 2010.

[49] A. Cicconetti, B. Sacchetti, A. Bartoli et al., "Human maxillary tuberosity and jaw periosteum as sources of osteoprogenitor cells for tissue engineering," Oral Surgery, Oral Medicine, Oral Pathology, Oral Radiology and Endodontology, vol. 104, no. 5, pp. 618.e1-618.e12, 2007.

[50] C. R. Irwin, M. Picardo, I. Ellis et al., "Inter-and intrasite heterogeneity in the expression of fetal-like phenotypic characteristics by gingival fibroblasts: potential significance for wound healing," Journal of Cell Science, vol. 107, no. 5, pp. 1333-1346, 1994.

[51] P. Stephens, K. J. Davies, N. Occleston et al., "Skin and oral fibroblasts exhibit phenotypic differences in extracellular matrix reorganization and matrix metalloproteinase activity," British Journal of Dermatology, vol. 144, no. 2, pp. 229-237, 2001.

[52] Q. Zhang, S. Shi, Y. Liu et al., "Mesenchymal stem cells derived from human gingiva are capable of immunomodulatory functions and ameliorate inflammation-related tissue destruction in experimental colitis," Journal of Immunology, vol. 183, no. 12, pp. 7787-7798, 2009.

[53] B. P. J. Fournier, F. C. Ferre, L. Couty et al., "Multipotent progenitor cells in gingival connective tissue," Tissue Engineering: Part A, vol. 16, no. 9, pp. 2891-2899, 2010.

[54] L. Tang, N. Li, H. Xie, and Y. Jin, "Characterization of mesenchymal stem cells from human normal and hyperplastic gingiva," Journal of Cellular Physiology, vol. 226, no. 3, pp. 832$842,2011$.

[55] T. Yamaza, G. Ren, K. Akiyama, C. Chen, Y. Shi, and S. Shi, "Mouse mandible contains distinctive mesenchymal stem cells," Journal of Dental Research, vol. 90, no. 3, pp. 317-324, 2011. 


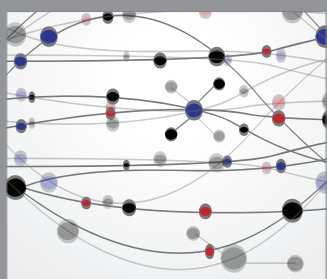

The Scientific World Journal
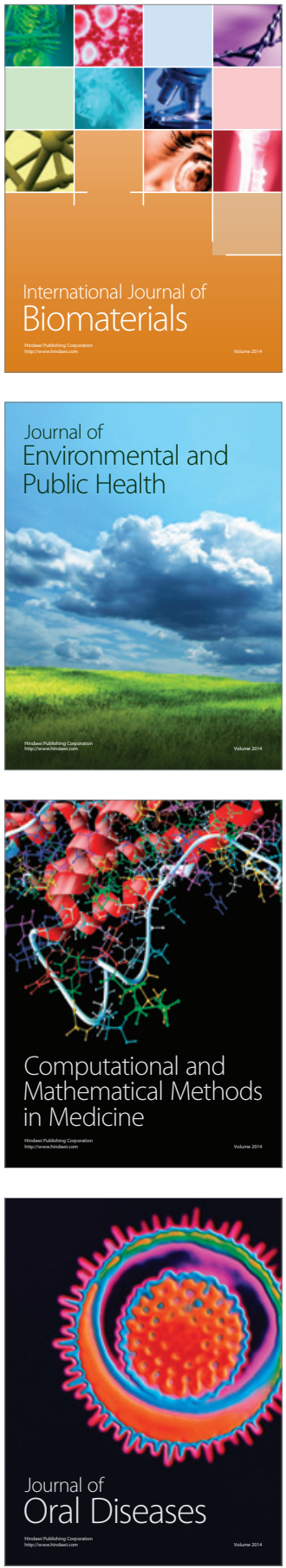
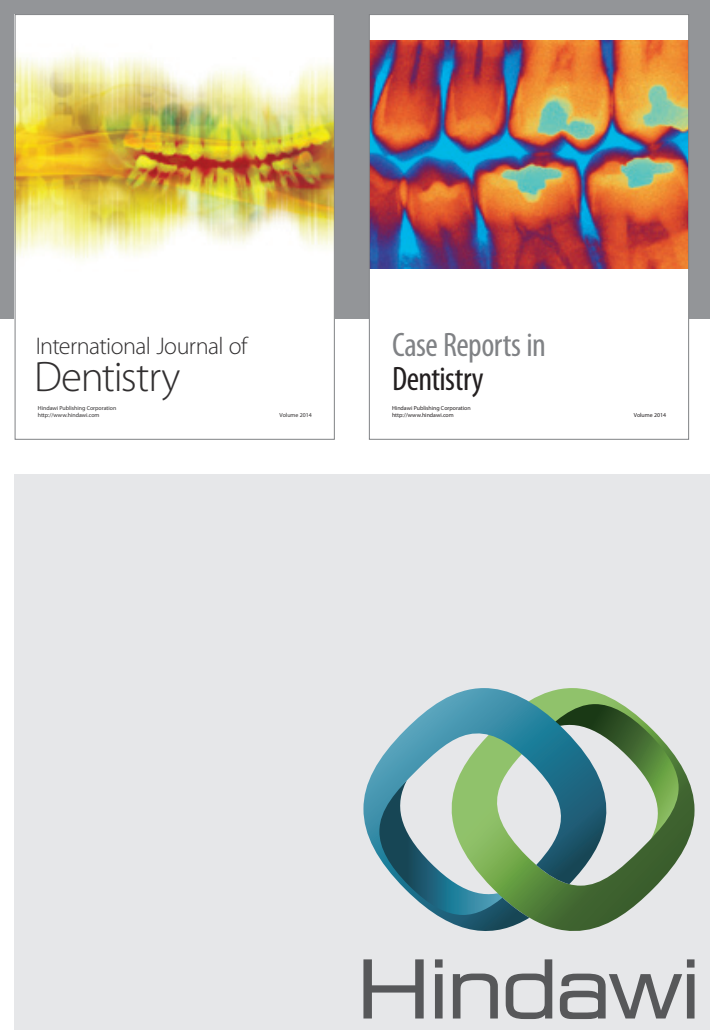

Submit your manuscripts at

http://www.hindawi.com
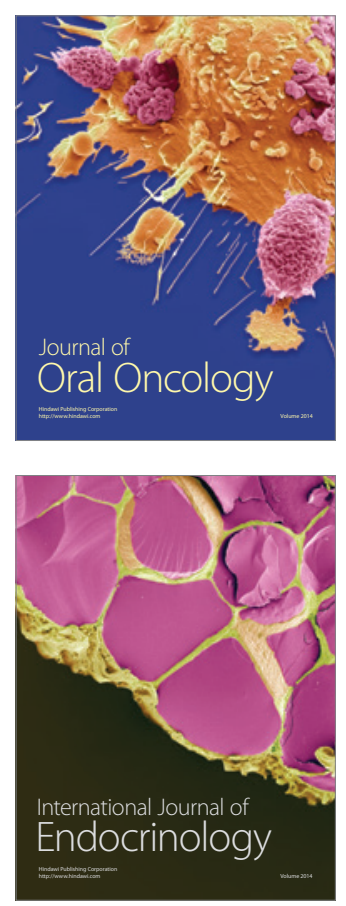
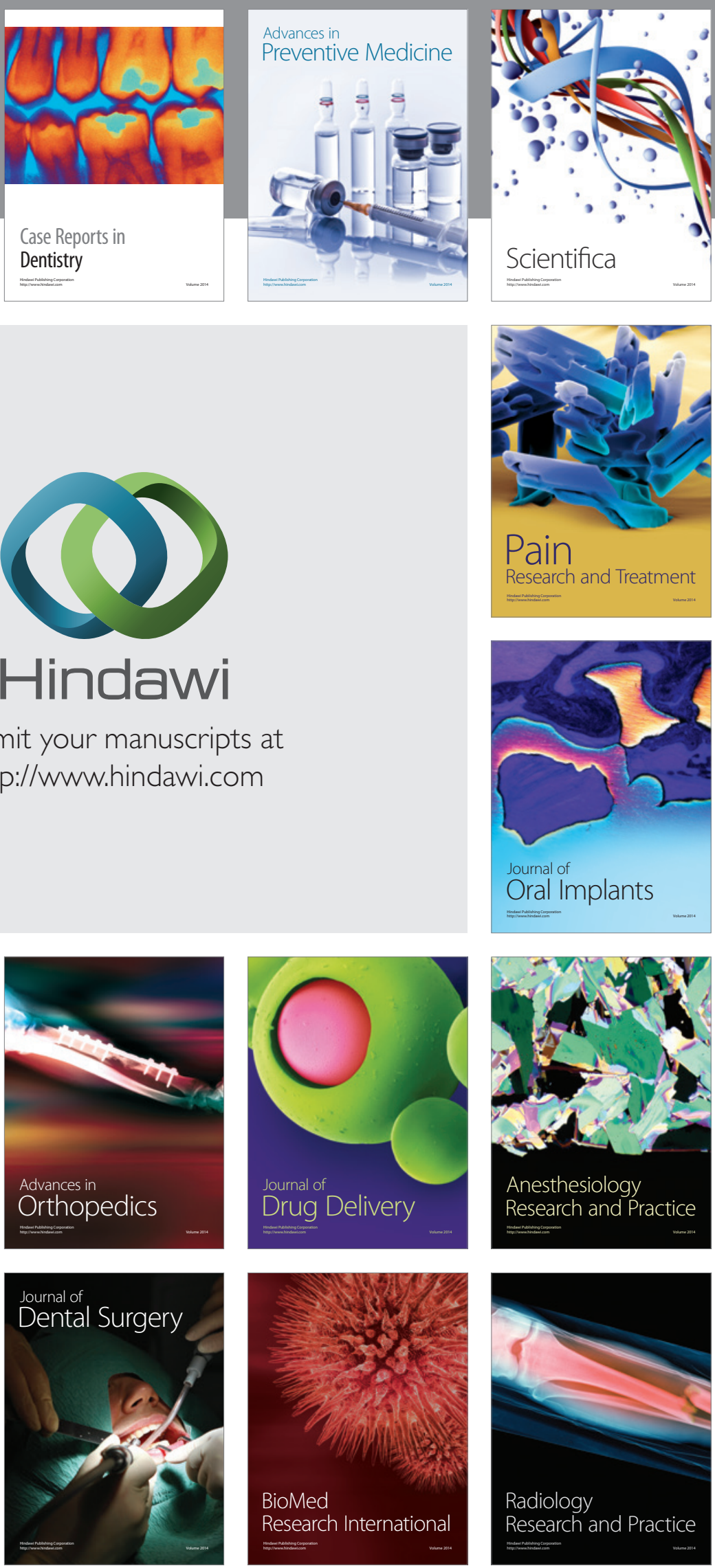